\title{
SELF-ORGANIZED MICRO-HONEYCOMB NETWORK STRUCTURE OF SINGLE-WALLED CARBON NANOTUBES FOR PHOTOVOLTAIC DEVICES
}

\author{
Shigeo Maruyama, Kehang Cui, Takaaki Chiba, Erik Einarsson and Shohei Chiashi \\ Department of Mechanical Engineering, The University of Tokyo \\ 7-3-1 Hongo, Bunkyo-ku, Tokyo 113-8656, Japan
}

\begin{abstract}
Single-walled carbon nanotubes (SWNTs) are expected to be a promising nanomaterial because of their outstanding electronic, mechanical, and thermal properties. For macroscopic device applications, an assembly of SWNTs is a critical issue. We propose a self-organized micro-honeycomb network structure of SWNTs obtained by water vapor treatment of as-synthesized vertically-aligned SWNTs (VA-SWNT) for solar cell devices with higher performance. The microhoneycomb structure was realized by simply exposing VASWNT to water vapor and drying in ambient condition. Honeycomb cell walls consist of capillary-aggregated vertically aligned SWNTs with heavily bundled top part. Within each cell, collapsed spaghetti-like SWNTs make contact to the substrate. The SWNT/n-Si heterojunction solar cell was built by placing the micro-honeycomb SWNTs network film on top of the substrate which has a $3 \mathrm{~mm} \times 3 \mathrm{~mm}$ bare n-type silicon contact window in the center. The contact window is surrounded by $\mathrm{SiO}_{2}$ as insulating layer and $\mathrm{Pt}$ as electrode. Our preliminary tests showed that optimal photovoltaic conversion efficiency (PCE) under AM1.5 was 5.91\%, with the fill factor of $72 \%$. The open-circuit voltage and short-circuit current are $0.53 \mathrm{~V}$ and $15.5 \mathrm{~mA} / \mathrm{cm}^{2}$, respectively. This showed a substantial improvement compared with heterojunction solar cells using spaghetti-like SWNTs. Furthermore, the superior performance of dye-sensitized solar cells with the microhoneycomb SWNTs was demonstrated.
\end{abstract}

\section{NOMENCLATURE}

J Current density $\left(\mathrm{mA} / \mathrm{cm}^{2}\right)$

$L \quad$ Thickness of vertically aligned SWNT film

V Bias voltage (V)

\section{INTRODUCTION}

Single-walled carbon nanotubes (SWNTs) are featured with outstanding electronic, optical, mechanical and thermal properties, hence considered as one of most promising material for next-generation electronic and optical devices such as field effect transistors (FET), photovoltaic devices and pulsed optical fiber laser. To bridge these nanoscale properties with corresponding performance of macroscale applications, the assembly of SWNTs is a critical issue. For photovoltaic devices, so far, spaghetti-like thin film of SWNTs known as bucky paper or vertically aligned SWNT (VA-SWNTs) have been examined for SWNT/Si heterojunction solar cells or counter electrode of dye-sensitized solar cells. Here, we propose a self-organized micro-honeycomb network structure of single-walled carbon nanotubes (SWNTs) obtained by water vapor treatment of as-synthesized VA-SWNTs for solar cell devices with higher performance.

The pursuit of high-efficiency carbon nanotube-based solar cells has long been an intriguing research topic since the discovery by Iijima in 1991 [1], yet still without any fundamental breakthrough and practical applications. In 2008, Cao group deposited double-walled carbon nanotube (DWNT) films onto n-type silicon substrate and showed the maximum PCE of 7\% [2]. Since then, this simple but efficient structure ignited great research interest worldwide. Wadhwa et al. [3] used SWNTs "buckypaper" with $\mathrm{SOCl}_{2}$ ionic liquid and obtained the efficiency of $8 \%$. SWNTs showed good performance but the fabrication process of SWNTs film included surfactant, sonication, vacuum filtration and liquid state doping chemicals which made the device life-time extremely short. The photo-conversion mechanism has been argued whether it is p-n junction or Schottky junction. In order to explore this mechanism of SWNT/n-silicon, Kozawa et al. used $(6,5)$ enriched CoMoCAT on top and obtained the PCE of $2.4 \%$ [4]. Ong et al. used SWNTs with $(7,6)$ major chirality, 


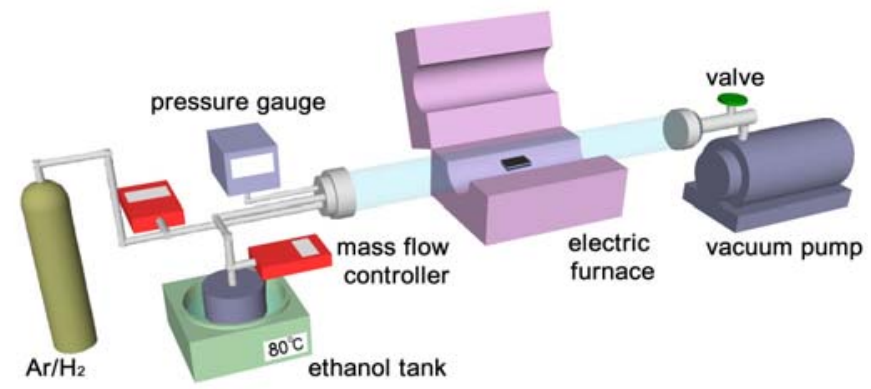

Fig. 1 Schematic of alcohol catalytic CVD system

and obtained the efficiency of $1.7 \%$ [5]. The same method was adopted by Jia et al. [6], and PCE was only $1.5 \%$. In order to dope the SWNTs more p-type, Saini et al. [7] employed borondoped SWNTs. However, the reached PCE was only $0.03 \%$. Film morphology and contact between nanotube and silicon is the most crucial limitation for further development of this device structure. In fact, SWNTs have long been suffering from the gap between the superior nanoscale properties and less pronounced microscale device characteristics.

As an earth-abundant element, carbon nanotubes have the potential to replace Pt and ITO as a counter electrode for dyesensitized solar cell. Lee et al [8] utilized bamboo-like structured multi-walled carbon nanotubes and obtained a PCE up to 7.7\%. Hao et al [9] found that the fill factor and PCE were improved after replacing Pt with VA-SWNTs. There is still a great space for the improvement using carbon nanotubes.

The capillary-based modification of nanotube network structure has been known long while. Chakrapani et al. [10] found that to immerse vertically-aligned multi-walled carbon nanotubes (MWNTs) film into acetone and dry thereafter would cause the shrinkage and cleavage of MWNTs film like mud and clay. Futaba et al. [11] also found the similar phenomena using super-growth vertically-aligned SWNTs film. John Hart and co-workers [12, 13] further developed the condensed MWNTs films into controllable 3-dimensional micro-architectures, including micro-honeycomb structure. Even though the controlling technique becomes more and more mature, no practical applications have been proposed to date.

In this paper, we have extended the morphology controlling technique to SWNTs which have pronounced electrical and optical properties. We have developed the selfassembled micro-honeycomb structure from high-quality VASWNTs, focusing on the photovoltaic applications. The photovoltaic performance of SWNTs films are demonstrated for two kinds of solar cells, the SWNT/n-Si heterojunction and dye-sensitized solar cells.

\section{GROWTH OF VERTICALLY ALIGHNED SWNTS}

VA-SWNTs were synthesized by the standard alcoholcatalytic CVD (ACCVD) [14, 15] method with Co/Mo dipcoated on quartz or $\mathrm{Si} / \mathrm{SiO}_{2}$ substrate [16]. The schematic of ACCVD system is shown in Fig. 1. The substrate loaded with

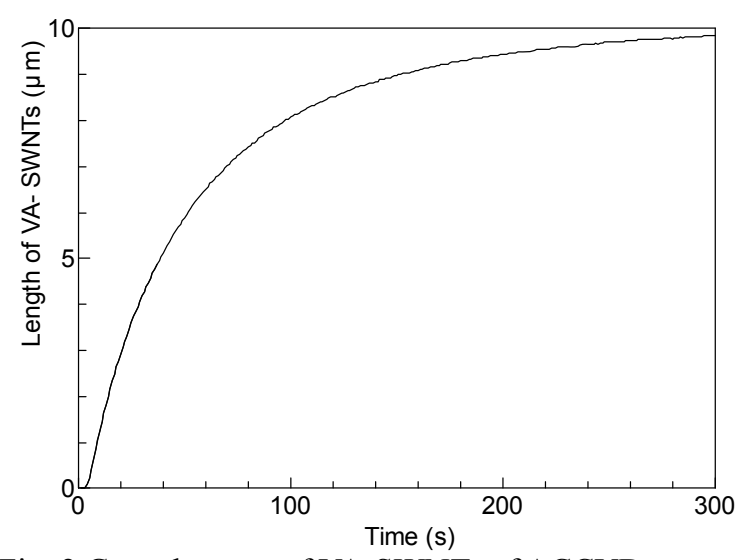

Fig. 2 Growth curve of VA-SWNTs of ACCVD process.

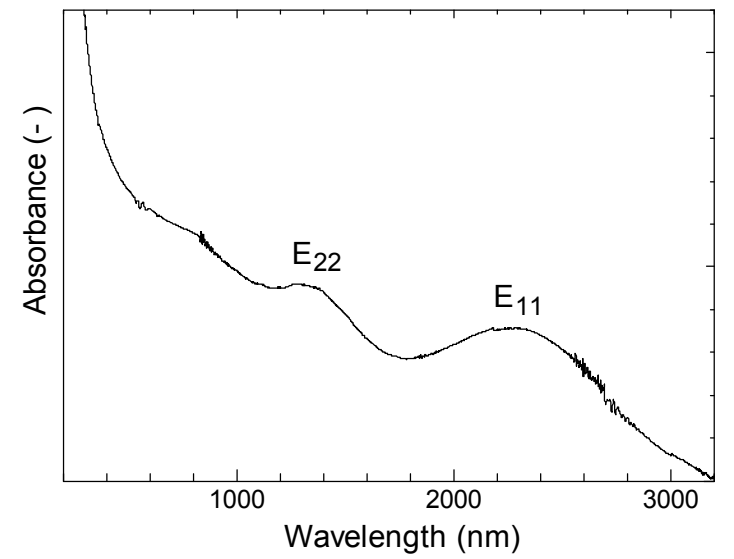

Fig. 3 UV-vis-NIR optical absorption of VA-SWNTs.

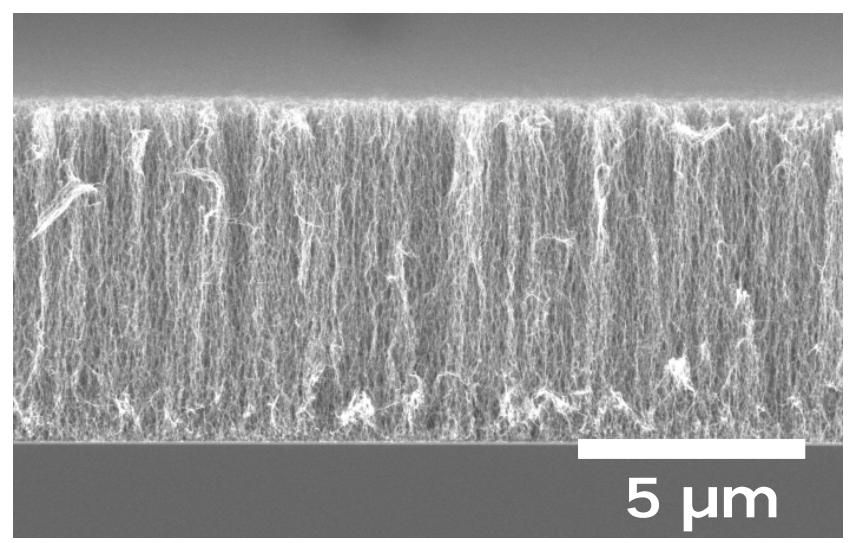

Fig. 4 SEM images of VA-SWNTs grown on quartz substrate. Growth time: 5min; SWNTs length: $10 \mu \mathrm{m}$.

Co/Mo bimetallic nanoparticle catalyst was placed in a quartz tube surrounded by the electric furnace after the dip-coating process and heated in a reduction environment gradually to 800 ${ }^{\circ} \mathrm{C}$ in $30 \mathrm{~min}$. Then, the substrate was kept at $800{ }^{\circ} \mathrm{C}$ for $10 \mathrm{~min}$ before ethanol feedstock was introduced with flow rate of 450 sccm at $1.3 \mathrm{kPa}$. The growth process of VA-SWNTs can be monitored by in-situ laser absorption technique [17, 18] for 


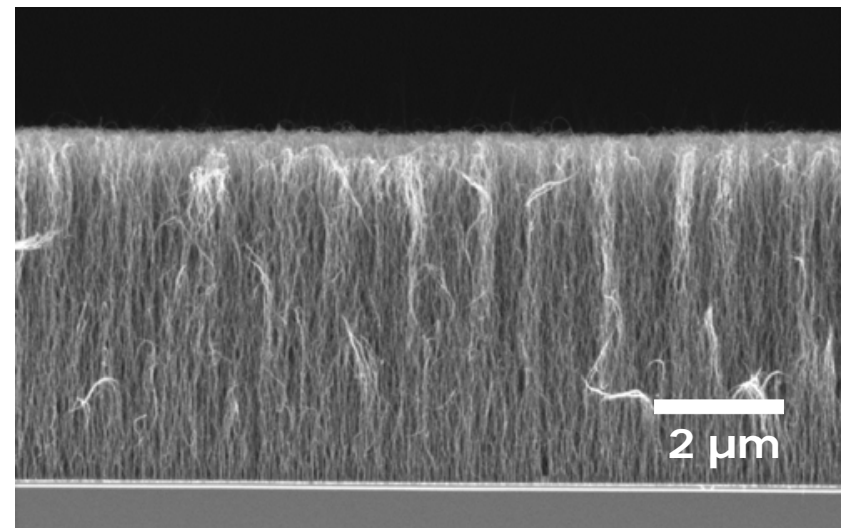

Fig. 5 SEM image of VA-SWNT sample grown on $\mathrm{Si} / \mathrm{SiO}_{2}$ substrate used for solar cell fabrication. Growth time: $25 \mathrm{~s}$; SWNT length: $5.2 \mu \mathrm{m}$.

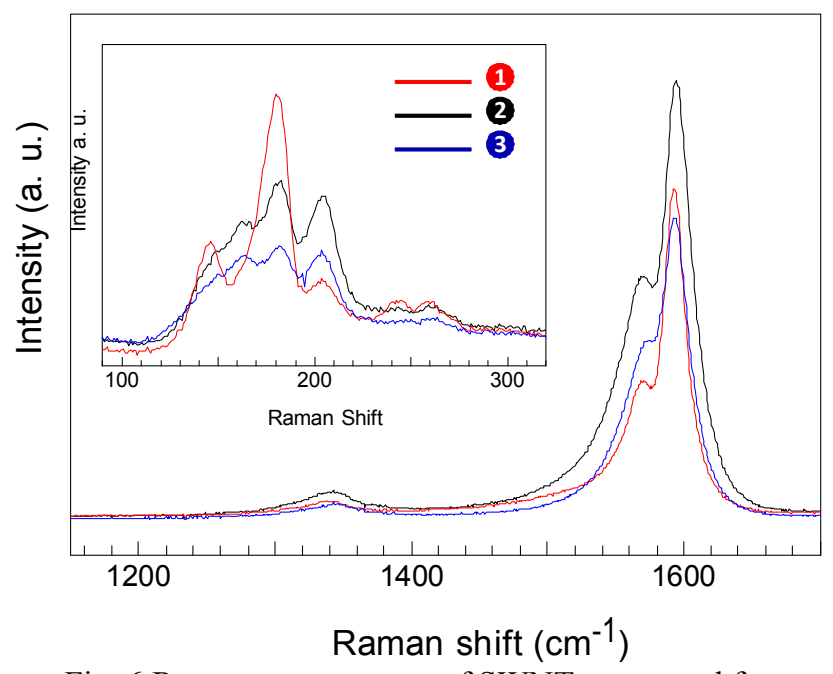

Fig. 6 Raman spectroscopy of SWNTs measured from different spots: spot 1 corresponds to pristine VA-SWNTs in Fig. 5. Spot 2 and 3 correspond to the same sample post vapor treatment (indicated in Fig. 8). Wavelength of excitation laser was $488 \mathrm{~nm}$.

quartz substrate. Fig. 2 and Fig. 3 show the growth process on quartz and SWNTs absorbance (Shimadzu UV-3150), respectively. From the absorbance in Fig. 3, the peak of $E_{11}$ is ca. 2400nm, which demonstrate the average diameter of SWNTs ca. $2 \mathrm{~nm}$ according to the Kataura plot [19]. The SEM (Hitachi S4800) image of the corresponding VA-SWNTs grown on quartz is shown in Fig. 4.

With the controlled growth technique, we grow SWNTs on $\mathrm{Si} / \mathrm{SiO}_{2}$ substrate with the length of $5 \mu \mathrm{m}$, as shown in the Fig. 5. As shown in Fig. 6, the ignorable D-band in the Raman spectroscopy demonstrated the high quality of VA-SWNTs. The radial breathing mode (RBM) demonstrated characteristic freestanding SWNTs feature around 160 and $181 \mathrm{~cm}^{-1}$ Raman shift [20]. The characteristic peaks become weaker after the water vapor treatment. This is more pronounced in the middle of
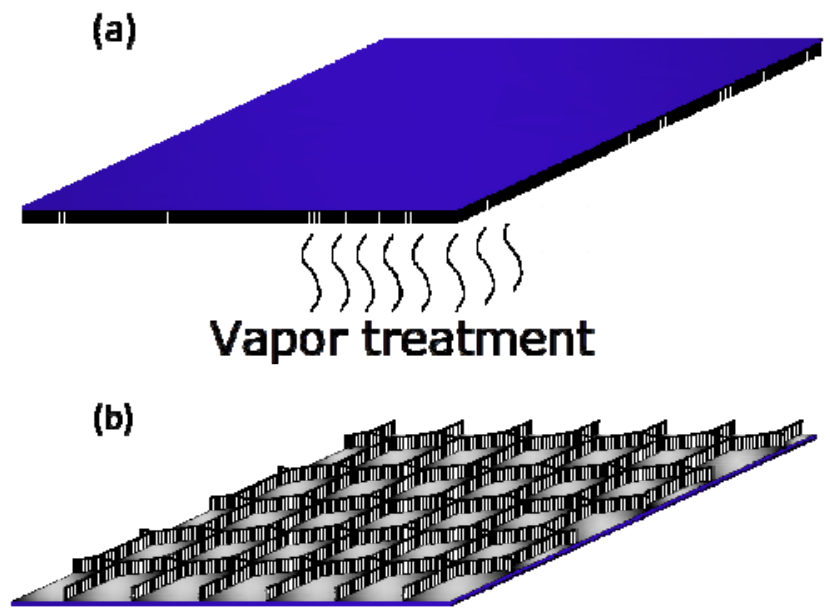

\section{Dry in ambient environment}

Fig. 7 Two steps of fabricating micro-honeycomb network of SWNTs films: (a) expose VA-SWNTs films in vapor with appropriate reservoir temperature and exposure time; (b) turn the samples upward and dry in ambient environment.

honeycomb cell where SWNTs are random spaghetti structure as in Fig. 6. Moreover, the VA-SWNT films can easily transferred onto any substrate by the hot-water method [21].

By modifying the concentration of $\mathrm{Co} / \mathrm{Mo}$ acetate solution and carbon stock, as well as substrate and CVD conditions, both the nanoscale and microscale of SWNTs could be controlled to a certain degree, respectively. On the nanoscale, the diameter of SWNTs could be tuned from $2.2 \mathrm{~nm}$ to $1.4 \mathrm{~nm}$ [19], which could change the band gap of semiconducting SWNTs drastically. Through the addition of acetonitrile to ethanol of the carbon stock, the diameter of nanotube could be changed from $2.1 \mathrm{~nm}$ to $0.7 \mathrm{~nm}$, respectively [22]. On the other hand, on the microscale, high-precision patterned growth of VA-SWNTs could be realized through tuning surface hydrophobicity of the substrate by the formation and removal of self-assembled [23].

\section{MICRO-HONEYCOMB NETWORK STRUCTURE OF SWNTS}

We propose here the water vapor treatment on high-quality VA-SWNTs to make micro-honeycomb network film. The whole process from film making to transfer needs only water and does not require any chemicals such as surfactant, organic solution or super acid etc., and power-consuming process such as sonication, evacuation etc. By the vapor treatment, microhoneycomb cell structure was obtained with capillary aggregated cell walls consist of vertically aligned SWNTs with heavily bundled top part. In the middle of each honeycomb cell, collapsed spaghetti-like SWNTs were formed in contact to the substrate. The vapor treatment include only two steps: 1) expose the VA-SWNTs films in vapor (Fig. 7 (a)) and 2) dry it in ambient environment (Fig. 7(b)). Depending on the 

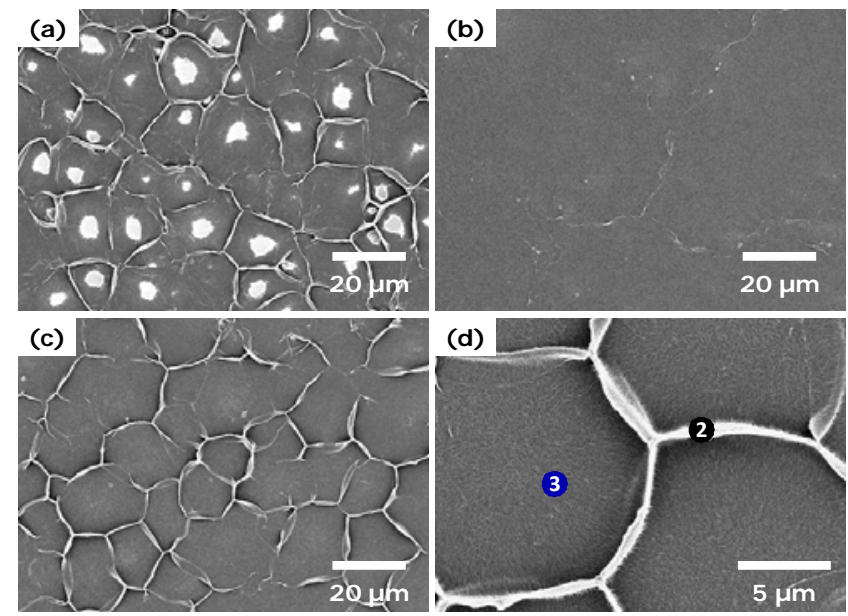

Fig. 8 (a, b, c) SEM images of different self-organizing network of SWNTs; (d) magnified image of condensed SWNTs bundles from (c).

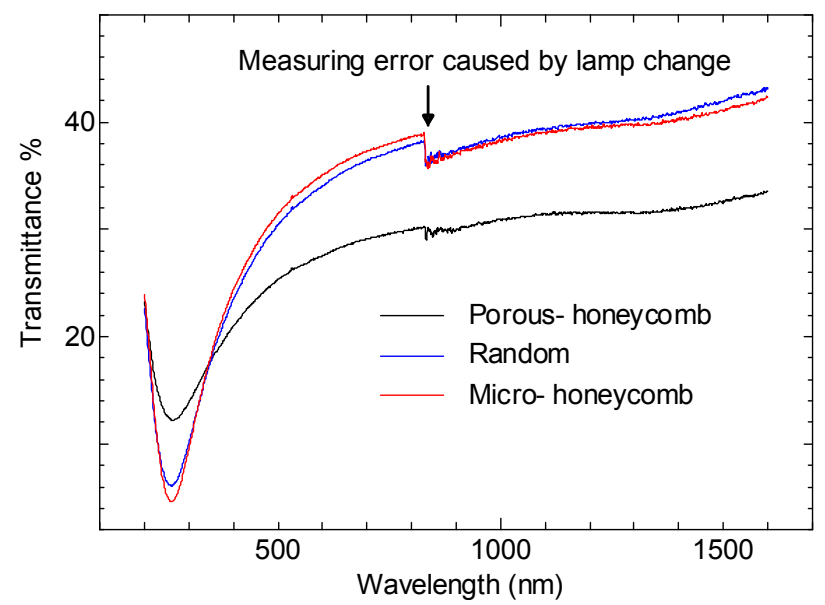

Fig. 9 Optical transmittance of vapor-treatment samples over the spectrum of $200 \mathrm{~nm}$ to $1600 \mathrm{~nm}$ wavelength.

temperature of water reservoir (which is about $5 \mathrm{~mm}$ below the substrate) and exposure time, the water condensate on the VASWNT film would exert different capillary forces and hence different cell size and morphology. The higher reservoir temperature and the longer exposure time increases the cell size.

Fig. 8 shows SEM images of honeycomb structure treated from about $5 \mu \mathrm{m}$ thick VA-SWNTs. Fig. 8 (a) shows that the random network of SWNTs in the middle of cell was split with a voids due to the poor wettability of water under low reservoir temperature $\left(\mathrm{T}<70^{\circ} \mathrm{C}\right)$ or lower vapor flux. At higher reservoir temperature $\left(\mathrm{T}>80^{\circ} \mathrm{C}\right)$, the spaghetti-like random network of nanotube films (shown in Fig. 8 (b)) were obtained by longer vapor exposure time $(\mathrm{t}>20 \mathrm{~s})$, while the micro-honeycomb structure could be obtained by shorter exposure time $(\mathrm{t} \approx 5 \mathrm{~s})$ (Fig 8(c)). More SEM images are shown in ANNEX A.
Table 1 Sheet resistance and optical transmittance of porous, spaghetti-like and micro-honeycomb structure

\begin{tabular}{|c|c|c|}
\hline & $\begin{array}{c}\text { Sheet resistance } \\
\Omega / \text { sq. }\end{array}$ & $\begin{array}{c}\text { Optical transmittance } \\
\text { at 550 nm wavelength }\end{array}$ \\
\hline $\begin{array}{c}\text { Porous- } \\
\text { honeycomb }\end{array}$ & 2996 & $26.6 \%$ \\
\hline $\begin{array}{c}\text { Spaghetti- } \\
\text { like random }\end{array}$ & 1079 & $32.5 \%$ \\
\hline $\begin{array}{c}\text { Micro- } \\
\text { honeycomb }\end{array}$ & 768 & $33.5 \%$ \\
\hline
\end{tabular}

The performance of the different SWNT films was characterized by sheet resistance and optical transmittance. The sheet resistance was measured by four-probe method (analyzer: Agilent 4156C; probe bed: Kyowa Riken K89PS) while the optical transmittance was obtained by UV-vis-NIR absorption equipment (Shimadzu UV-3150). As shown in Table 1, microhoneycomb structure film has the highest transmittance and lowest sheet resistance. This could be attributed to that in micro-honeycomb structure, the highly condensed SWNT "walls" act as electron carrier highway so that it exhibit superior conductance than the spaghetti-like random network. This structure was clearly described in the magnified SEM image as shown in Fig. 8(d). Meanwhile, as in each microhoneycomb cell the nanotubes were pushed down uniformly to the substrate, its transmittance is also the highest.

\section{HETEROJUNCTION SOLAR CELL}

The cross-sectional view of the fabricated SWNT/n-Si heterojunction solar cell is shown in Fig. 10. The solar cell was composed of SWNTs and the substrate which has a $3 \mathrm{~mm} \times 3$ $\mathrm{mm}$ bare n-type silicon (CZ growth, $<100>$ axis, $7.5-12.5 \Omega \cdot \mathrm{cm}$, $100 \mathrm{~nm} \mathrm{SiO}$, Lot\# 1-41072-000, SUMCO Co.) contact window in the center. The contact window is surrounded by $\mathrm{SiO}_{2}$ as insulating layer and $\mathrm{Pt}$ as electrode. Depending on the chiralities of SWNTs, the heterojunction could have two different band diagrams, as shown in Fig. 11 [5]. The semiconducting SWNTs in contact with Si are p-doped when exposed in air, so the $\mathrm{p}-\mathrm{n}$ heterojunction would be formed between SWNTs and n-type silicon; while the metallic SWNTS and n-type silicon would become Schottky junction [6]. In our experiment, the majority diameter of SWNTs in ACCVD is 2

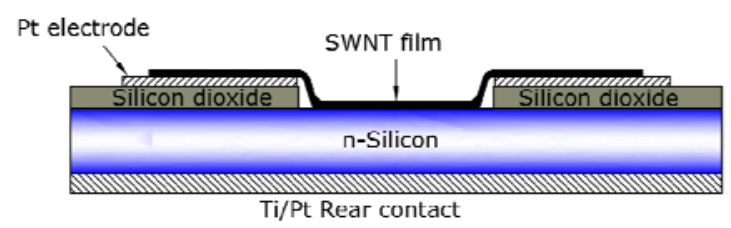

Fig. 10 Schematic of SWNT/n-Si heterojunction solar cell. 

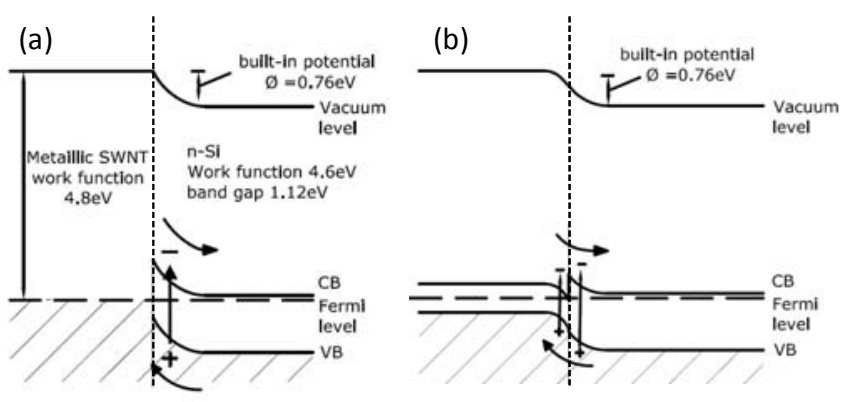

Fig. 11 Proposed band diagram of SWNT/n-Si heterojunction solar cell [5].

$\mathrm{nm}$, so that the built-in potential for the excited charge carrier separation could be roughly calculated as $0.76 \mathrm{eV}$.

The n-type silicon used for the substrate was treated with $5 \mathrm{M} \mathrm{NaOH}$ under $90{ }^{\circ} \mathrm{C}$ for $60 \mathrm{~min}$ to remove the native oxide The serial resistance of the silicon is $7.5-13.5 \Omega / \mathrm{cm}$. Then the silicon was soaked in RCA2 cleaning solution, which is the mixture of $\mathrm{H}_{2} \mathrm{O}: \mathrm{HCl}: \mathrm{H}_{2} \mathrm{O}_{2}=5: 1: 1$ for 10 min with bath sonication. The silicon was rinsed for several times by dionized water under $\mathrm{pH} 7$ before $200 \mathrm{~nm} \mathrm{SiO}_{2}$ was sputtered on the surface with a $3 \mathrm{~mm}$ by $3 \mathrm{~mm}$ bare silicon window open. The front and rear contact electrodes were $\mathrm{Pt}$ and $\mathrm{Ti} / \mathrm{Pt}$, respectively. Finally, the SWNT films were transferred onto the substrate by hot-water technique.

The J-V characteristic of solar cell samples were tested under standard AM 1.5 and dark conditions, which is shown in Fig. 12. The optimal photovoltaic conversion efficiency (PCE) for micro-honeycomb network heterojunction solar cell under AM1.5 was $5.91 \%$, with the fill factor of $72 \%$. This fill factor is the highest record among the SWNT/n-Si heterojunction solar cells without liquid chemical doping. The open-circuit voltage and short-circuit current are $0.53 \mathrm{~V}$ and $15.54 \mathrm{~mA} / \mathrm{cm}^{2}$, respectively. This showed a $13.2 \%$ and $29.7 \%$ improvement compared with heterojunction solar cells using spaghetti-like and porous-honeycomb SWNTs, of which the PCE were 5.22\% and $4.56 \%$, respectively. The short-circuit current demonstrated the inversely proportional dependence on the transmittance shown in table 1 . This could be attributed that more photon energy reached to the interface of nanotube/Si junction, more exitions would be excited and collected. In the microhoneycomb structure, each honeycomb cell is comprised of thinner and uniform spaghetti-like nanotube films. Compared with normal spaghetti-like nanotube film, large quantities of nanotubes in the micro-honeycomb structure were selfassembled into walls, so that more photon energy was transmitted to the interface and efficiently collected by the walls. The fill factor increased with the decreasing sheet resistance. Series resistance inside this heterojunction solar cell is the sum of the sheet resistance of SWNT films and the contact resistance between SWNT films and electrodes. For the micro-honeycomb structure, the condensed SWNT walls contributed substantially to the sheet resistance decrease, hence

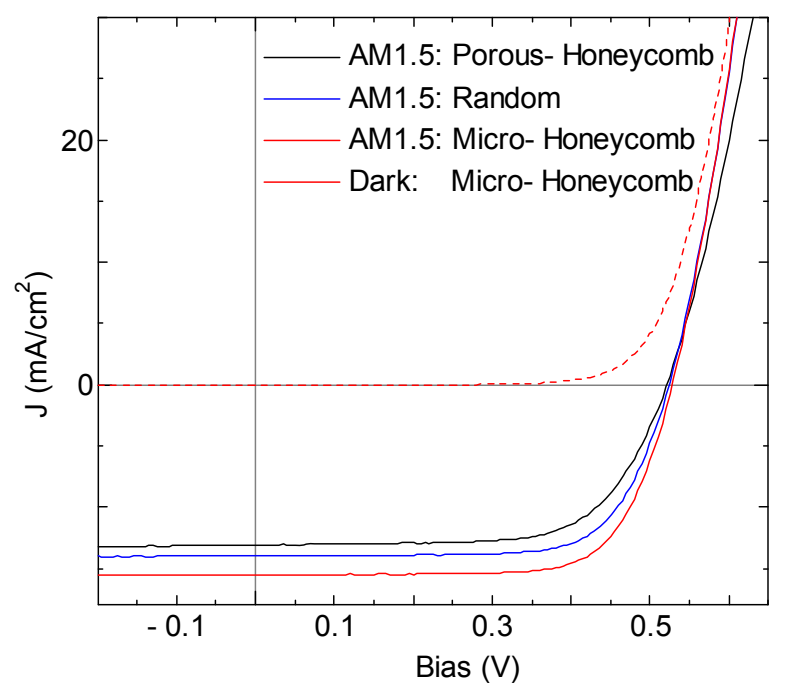

Fig. $12 \mathrm{~J}-\mathrm{V}$ characteristic of $\mathrm{SWNT} / \mathrm{Si}$ heterojunction solar cell with porous-honeycomb, random and microhoneycomb network measured under AM1.5 condition and dark.

a greater fill factor. More $\mathrm{J}-\mathrm{V}$ characteristics related with different morphologies could be found in ANNEX B.

\section{DYE-SENTITIZED SOLAR CELL}

The application of the micro-honeycomb SWNTs was examined for counter electrode of dye-sensitized solar cells (DSSC) [22]. As shown in Fig. 13, fabricated DSSC is composed of photo electrode, electrolyte and counter electrode. The photo electrode was composed fluorine tin oxide (FTO) glass and a layer of nanocrystalline $\mathrm{TiO}_{2}$ particles with thickness of $10 \mu \mathrm{m}$. The photo electrode was heated to $450{ }^{\circ} \mathrm{C}$ for $30 \mathrm{~min}$ and annealed in air. It was then immersed into 0.3 mM N719 solution in ethanol for $24 \mathrm{~h}$. The N719-incorporated

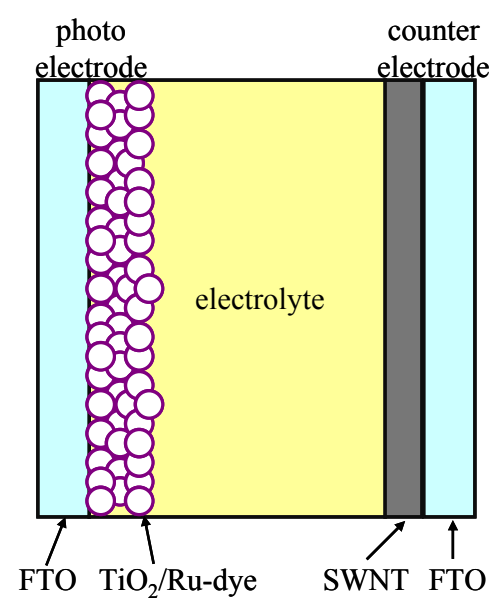

Fig. 13 Schematic of dye-sensitized solar cell with SWNT counter electrode. 


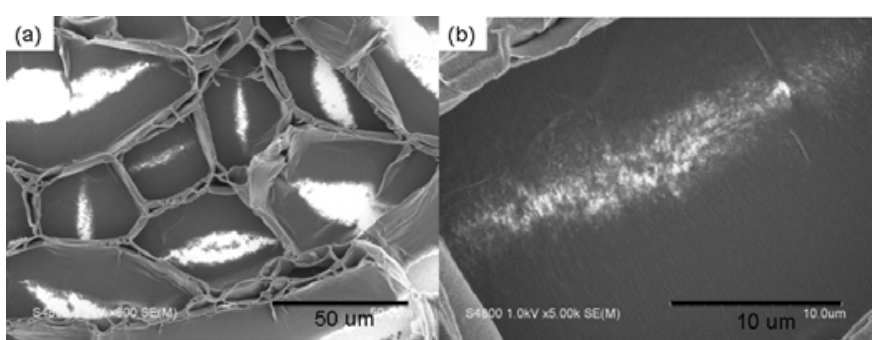

Fig. 14 (a) SEM images of self-organizing micro-honeycomb network of SWNT. (b) magnified image.

electrode was carefully rinsed by ethanol.

The counter electrode is usually composed of FTO glass and sputtered Pt. Replacing Pt with SWNTs or graphene has been examined in many groups [23]. Here, we compared as grown VA-SWNT with thickness of $27 \mu \mathrm{m}$ and vapor treated micro-honeycomb film. In order to ensure the catalytic performance of SWNTs, we need to use the thicker film of VASWNTs compared with the heterojunction solar cell. From our preliminary examination, water vapor was not much effective for this thick VA-SWNTs. Hence, VA-SWNT was exposed in ethanol vapor for $1 \mathrm{~s}$ for the structure shown in Fig. 14. Then, the film was transferred onto FTO glass by hot water method.

DSSC was fabricated by placing photo electrode on counter electrode with scotch tape of $50 \mu \mathrm{m}$ as the spacer. The redox electrolyte was introduced into the cell through a slit by capillary force.

The J-V characteristics of DSSCs were tested under standard AM 1.5 as shown in Fig. 15. PCE for microhoneycomb counter electrode DSSC under AM 1.5 was $4.64 \%$, with the fill factor $54 \%$. The open-circuit voltage and short-circuit current were $0.70 \mathrm{~V}$ and $12.24 \mathrm{~mA} / \mathrm{cm}^{2}$. This showed $10 \%$ improvement compared with VA-SWNT counter electrode DSSC, of which the PCE was $4.20 \%$.

\section{SUMMARY}

In this paper we demonstrated that the micro-honeycomb network of SWNTs possessed advantageous properties in SWNT/n-Si heterojunction solar cells, owing to the higher electrical conductance and optical transmittance. Furthermore, this 3-dimensional structure may have the possibility of further applications in organic or dye-sensitized solar cell, due to their hierarchical morphology simple and low-cost fabrication process.

\section{ACKNOWLEDGMENTS}

Part of this work was financially supported by Grant-inAid for Scientific Research (22226006, 23760180, 23760179, 25630063). This work was also supported by the VLSI Design and Education Center (VDEC), The University of Tokyo, in collaboration with Cadence Corporation.

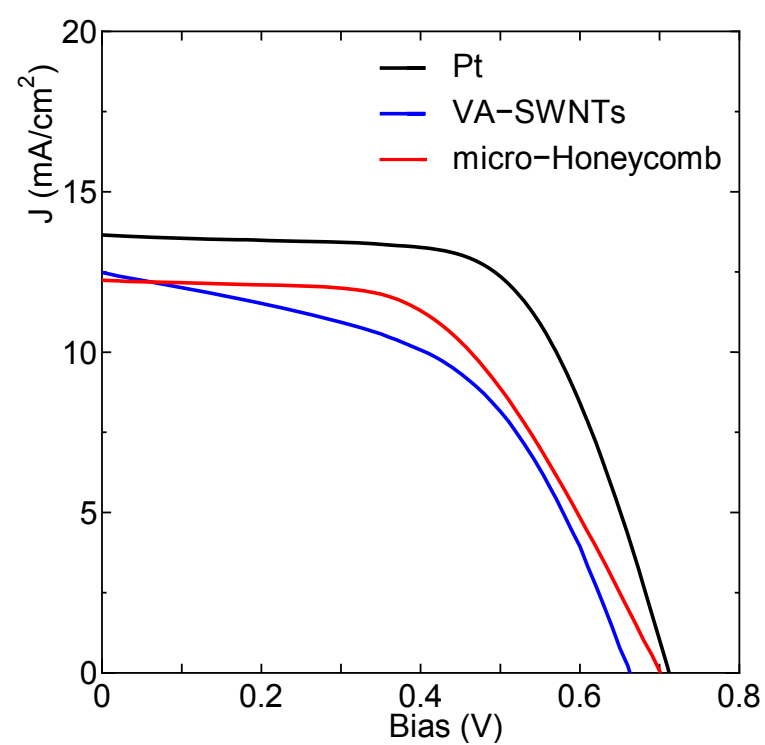

Fig. $15 \mathrm{~J}-\mathrm{V}$ characteristic of DSSC with Pt counter electrode, VACNT counter electrode and micro-Honeycomb counter electrode under AM1.5 condition.

\section{REFERENCES}

[1] Iijima, S., 1991, "Helical microtubules of graphitic carbon," Nature, 354, pp. 56-58.

[2] Jia, Y., Wei, J., Wang, K., Cao, A., Shu, Q., Gui, X.,Zhu, Y., Zhuang, D., Zhang, G., Ma, B., Wang, L., Liu, W., Wang, Z., Luo, J., and Wu, D., 2008, "Nanotube-Silicon Heterojunction Solar Cells," Adv. Mat., 20, pp. 4594-4598.

[3] Wadhwa, P., Liu, B., McCarthy, M. A., Wu, Z., and Rinzler, A. G., 2012, "Electronic Junction Control in a NanotubeSemiconductor Schottky Junction Solar Cell," Nano Lett., 10, pp. 5001-5005.

[4] Kozawa, D., Hiraoka, K., Miyauchi, Y., Mouri, S., and Matsuda, K., 2012 "Analysis of the Photovoltaic Properties of Single-Walled Carbon Nanotube/Silicon Heterojunction Solar Cells," Appl. Phys. Express, 5, pp. 042304-042306.

[5] Ong, P., Euler, W., and Levitsky, I. A., 2012, "Hybrid solar cells based on single-walled carbon nanotubes/Si heterojunctions," Nanotechnology, 21, pp. 105203-105209.

[6] Jia, Y., Li, P., Wei, J., Cao, A., Wang, K., Li, C., Zhuang, D., Zhu, H., and Wu, D., 2012, "Carbon nanotube films by filtration for nanotube-silicon heterojunction solar cells," 45, pp. 1401-1405.

[7] Saini, V., Li, Z., Bourdo, S., Kunets, V. P., Trigwell, S., Couraud, A., Rioux, J., Boyer, C., Nteziyaremye, V., Dervishi, E., Bors, A. R., Salamo, G. J., Viswanathan, T., and Biris, A., 2011, "Photovoltaic devices based on high density boron-doped single-walled carbon nanotube/n-Si heterojunctions," J. Appl. Phys., 109, pp. 014321-014307.

[8] Lee, W. J., Ramasamy, E., Lee, D. Y., Song J. H., 2009, "Efficient dye-sensitized solar cells with catalytic multiwall 
carbon nanotube counter electrodes", ACS Appl. Mater. Interfaces, 6, pp. 1145-1149

[9] Hao, F., Dong, P., Zhang, J., Zhang, Y., Loya, P. E., Hauge, R. H., Li, J., Lou, J., Lin, H., 2012, "High electrocatalytic activity of vertically aligned single-walled carbon nanotubes towards sulfide redox shuttles", Sci. Rep., 2, No. 368

[10] Chakrapani, N., Wei, B., Carrillo, A., Ajayan, P. M., and Kane, R. S., 2003, "Capillarity-driven assembly of twodimensional cellular carbon nanotube foams," Proc. Nat. Acad. Sci., 101, pp. 4009-4012.

[11] Futaba, D. N., Hata, K., Yamada, T., Hiraoka, T. Hayamizu, Y., Tanaike, O., Yumura, M., and Iijima, S., 2006, "Shape-engineerable and highly densely packed single-walled carbon nanotubes and their application as super-capacitor electrodes," Nat. Mat., 5, pp. 987-994.

[12] De Volder, M., Tawfick, S. H., Park, S. J., Copic, D., Zhao, Z., Lu, W., and Hart, A. J., 2012, "Diverse 3D Microarchitectures Made by Capillary Forming of Carbon Nanotubes," Adv. Mat., 22, pp. 4384-4389.

[13] Tawfick, S., De Volder, M., Hart, A. J., 2011, "Structurally Programmed Capillary Folding of Carbon Nanotube Assemblies," Langmuir, 27, pp. 6389-6394

[14] Maruyama, S., Kojima, R., Miyauchi, Y., Chiashi, S., and Kohno, M., 2002, "Low-temperature synthesis of high-purity single-walled carbon nanotubes from alcohol," Chem. Phys. Lett., 360, pp. 229-234.

[15] Murakami, Y., Chiashi, S., Miyauchi, Y., Hu, M. H., Ogura, M., Okubo, T., and Maruyama, S., 2004, "Growth of vertically aligned single-walled carbon nanotube films on quartz substrates and their optical anisotropy," Chem. Phys. Lett., 385, pp. 298-303.

[16] Murakami, Y., Miyauchi, Y., Chiashi, S., and Maruyama, S., 2003, "Direct synthesis of high-quality single-walled carbon nanotubes on silicon and quartz substrates," Chem. Phys. Lett., 377, pp. 49-54.

[17] Maruyama, S., Einarsson, E., Murakami, Y., and Edamura, T., 2005, "Growth process of vertically aligned single-walled carbon nanotubes," Chem. Phys. Lett., 403, pp. 320-323.

[18] Einarsson, E., Murakami, Y., Kadowaki, M., and Maruyama, S., 2008, "Growth dynamics of vertically aligned single-walled carbon nanotubes from in situ measurements," Carbon, 46, pp. 923-930

[19] Xiang, R., Einarsson, E., Murakami, Y., Shiomi, J., Chiashi, S., Tang, Z. and Maruyama, S., 2012, "Diameter Modulation of Vertically Aligned Single-Walled Carbon Nanotubes," ACS Nano, 6, pp. 7472-7479.

[20] Zhang, Z. Y., Einarsson, E., Murakami, Y., Miyauchi, Y., and Maruyama, S., 2010, "Polarization dependence of radial breathing mode peaks in resonant Raman spectra of vertically aligned single-walled carbon nanotubes," Phys. Rev. B, 81, pp. 165442-1-165442-9.

[21] Murakami, Y., and Maruyama, S., 2006, "Detachment of vertically aligned single-walled carbon nanotube films from substrates and their re-attachment to arbitrary surfaces," Chem. Phys. Lett., 422, pp. 575-580.
[22] Thurakitseree, T., Kramberer, C., Zhao, P., Aikawa, S., Harish, S., Chiashi, S., Einarsson, E. and Maruyama, S., 2012, "Diameter-controlled and nitrogen-doped vertically aligned single-walled carbon nanotubes," Carbon, 7, pp. 2635-2640.

[23] Xiang, R., Wu, T., Einarsson, E., Suzuki, Y., Murakami, Y., Shiomi, J. and Maruyama, S., 2009, "High-Precision Selective Deposition of Catalyst for Facile Localized Growth of Single-Walled Carbon Nanotubes," J. Am. Chem. Soc., 131, pp. 10344-10345.

[24] O’Regan, B. and Gratzel, M., 1991, "A low-cost, highefficiency solar cell based on dye-sensitized colloidal $\mathrm{TiO}_{2}$ films," Nature, 353, pp. 737-740.

[25] Yang, Z., Li, L., Lin, H., Luo, Y., He, R., Qiu, L., Ren, J. and Peng, H., 2012, "Penetrated and aligned carbon nanotubes for counter electrodes of highly efficient dye-sensitized solar cells," Chem. Phys. Lett., 549, pp. 82-86. 
ANNEX A

SEM IMAGES OF MICRO-HONEYCOMB NETWORK
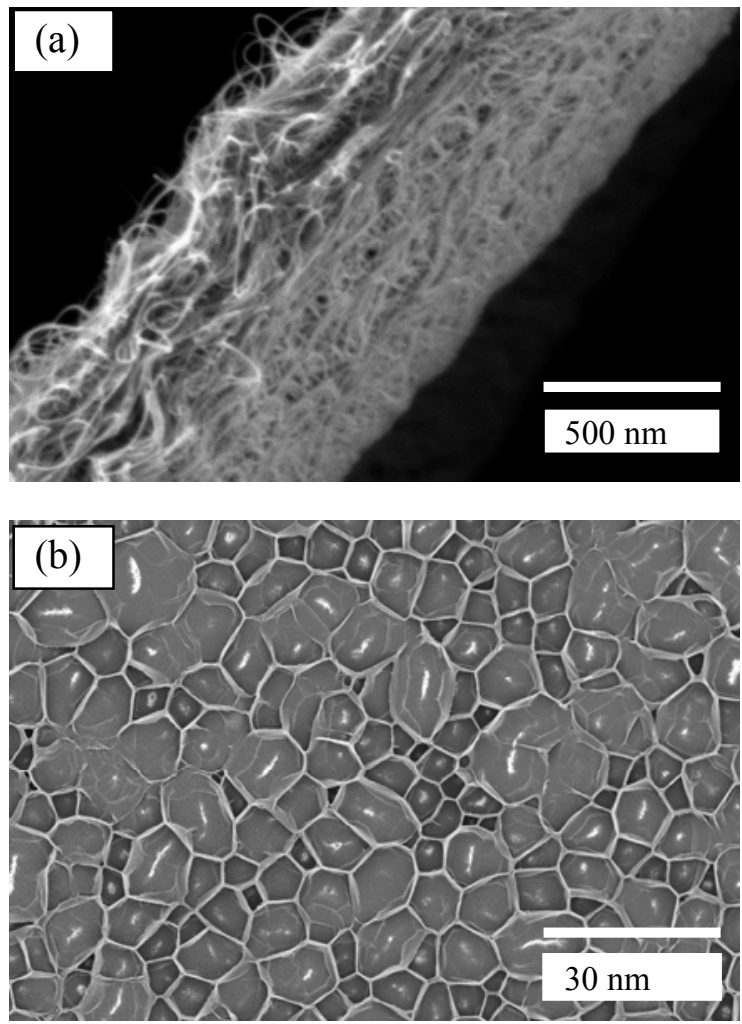
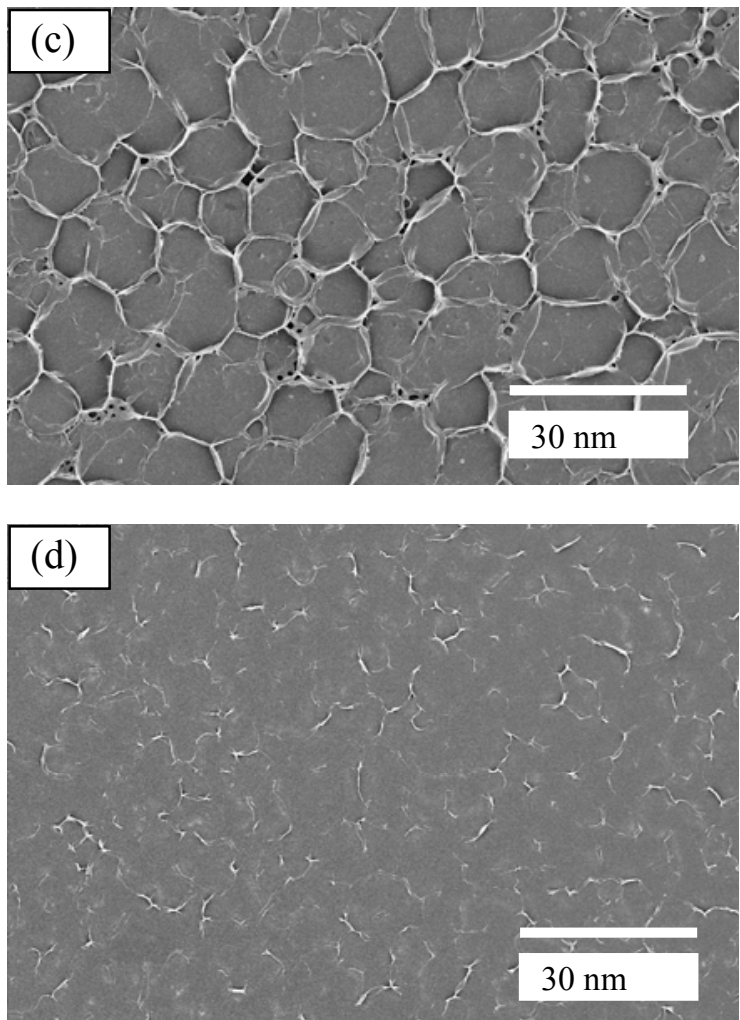

Fig. A. (a) magnified SEM images of condensed SWNT "walls"; (from b to d) shows that with longer vapor exposure time and higher vapor temperature, the micro-honeycomb structure was gradually changed to spaghetti-like random network.

Table A. Fabrication parameters for the morphologies in Fig. A

\begin{tabular}{|c|c|c|c|}
\hline & $\begin{array}{c}\text { Length of VA- } \\
\text { SWNT }(\mu \mathrm{m})\end{array}$ & $\begin{array}{c}\text { Vapor exposure } \\
\text { time }(\mathrm{s})\end{array}$ & $\begin{array}{c}\text { Reservoir } \\
\text { temperature }\left({ }^{\circ} \mathrm{C}\right)\end{array}$ \\
\hline $\mathrm{b}$ & 5 & 3 & 80 \\
\hline $\mathrm{c}$ & 5 & 4 & 80 \\
\hline $\mathrm{d}$ & 3 & 5 & 80 \\
\hline
\end{tabular}




\section{ANNEX B}

DIFFERENT SWNT MORPHOLOGIES AND CORRESPONDING J-V CHARACTERISTICS
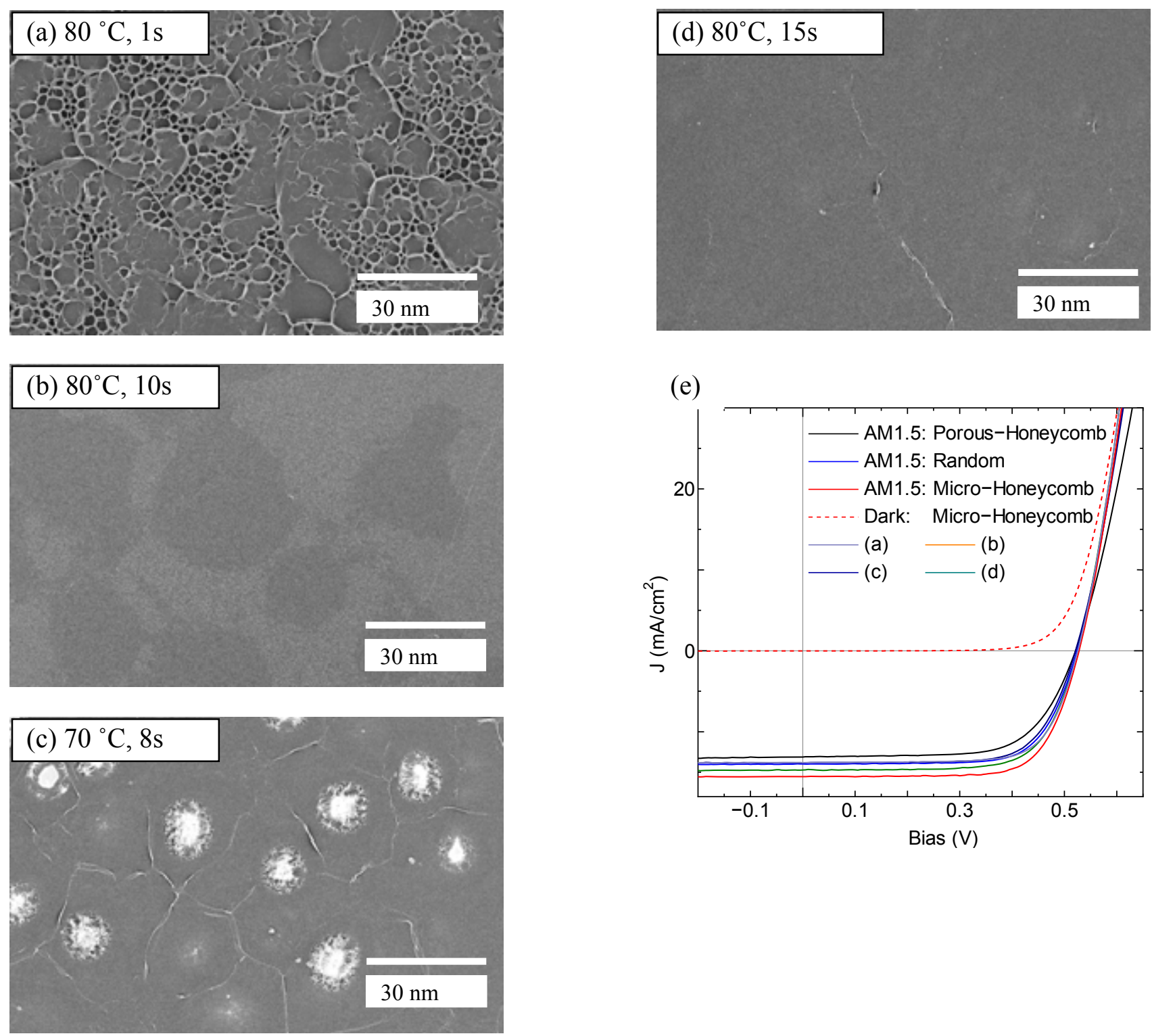

B. (a-d) SEM images of different morphologies obtained by vapor treatment and (e) corresponding J-V characteristics. The PCE of samples a, b, c and d are 5.27\%, 5.18\%, 5.07\% and 5.45\%, respectively. Of all the samples, the initial thickness of VA-SWNT film was $5 \pm 0.2 \mu \mathrm{m}$. 